\title{
Carbon Modified with Vanadium Nanoparticles for Hydrogen Peroxide Electrogeneration
}

\author{
P. S. Simas ${ }^{1}$ - V. S. Antonin ${ }^{1}$ - L. S. Parreira ${ }^{1}$ - P. Hammer ${ }^{2}$ - F. L. Silva ${ }^{3} \cdot$ M. S. Kronka ${ }^{3}$. \\ R. B. Valim ${ }^{3}$ M. R. V. Lanza ${ }^{3}$ - M. C. Santos ${ }^{1}$
}

Published online: 11 April 2017

(C) Springer Science+Business Media New York 2017

\begin{abstract}
This paper compares the results of two preparation routes for the production of carbon (Vulcan XC 72R) modified with vanadium nanostructured electrocatalysts for hydrogen peroxide $\left(\mathrm{H}_{2} \mathrm{O}_{2}\right)$ electrogeneration using the following mass proportions of vanadium on carbon $(\mathrm{V} / \mathrm{C}): 1,3,5,7$, 10 , and $13 \%$. Best results for $\mathrm{H}_{2} \mathrm{O}_{2}$ electrogeneration were obtained using a V/C sol-gel method (SGM) with $3 \%$, highest ring currents. For oxygen reduction reaction (ORR), using the V/C SGM with $3 \%$ and V/C polymeric precursor method (PPM) with 7\%, the results of ring currents measured are very high when compared to Vulcan XC 72R. X-ray diffraction (XRD) analysis mainly showed the $\mathrm{V}_{2} \mathrm{O}_{5}$ phase. X-ray photoelectron spectroscopy (XPS) results of the V/C PPM 7\% and V/C SGM 3\% samples highlight the predominance of the $\mathrm{V}_{2} \mathrm{O}_{5}$ phase and, for the latter catalyst, a more oxidized carbon surface. For the most promising electrocatalysts, the contact angle was evaluated, showing that the anchoring of the metal in the carbon surface increases the hydrophilicity of the materials. The prepared materials are promising for peroxide electrogeneration mainly due to the synergetic effect of vanadium oxide nanoparticles and acid oxygen species of the carbon, contributing to enhancing catalyst hydrophilicity.
\end{abstract}

M. C. Santos

mauro.santos@ufabc.edu.br

1 LEMN, Centro de Ciências Naturais e Humanas (CCNH), Universidade Federal do ABC (UFABC), Rua Santa Adélia 166, Bairro Bangu, Santo André, SP 09210-170, Brazil

2 Instituto de Química, Universidade Estadual Paulista (UNESP), Araraquara, SP 14800-060, Brazil

3 Instituto de Química de São Carlos, Universidade de São Paulo, Caixa Postal 780, São Carlos, SP 13566-590, Brazil
Keywords Carbon XC 72R · Vanadium nanostructured materials $\cdot$ Hydrogen peroxide $\cdot$ Advanced oxidative processes $\cdot$ Oxygen reduction reaction

\section{Introduction}

Regulations for the use of new chemicals that cause serious damage to the environment even at low concentrations are critical [1-5]. In addition to the contamination of living beings through direct contact with these compounds, the action of rain intensified by leaching effects [6] leads to the contamination of soil, rivers, and groundwater and, consequently, to all of the fauna and flora of the ecosystem. Due to the serious impacts caused by inadequate management, treatment of toxic industrial wastewater is an issue of great interest and has been the focus of a number of studies [7-11].

One important approach of remediation is based on advanced oxidative processes (AOPs), which are clean, non-selective, and able to degrade a number of hazardous compounds by the generation of highly oxidizing hydroxyl radicals $(\cdot \mathrm{OH})$, which can occur through the following processes $[1,2,8-11]$ : (i) reactions with a semiconductor particle, such as titanium dioxide $\left(\mathrm{TiO}_{2}\right)$; (ii) reactions involving ozone $\left(\mathrm{O}_{3}\right)$; (iii) the use of hydrogen peroxide $\left(\mathrm{H}_{2} \mathrm{O}_{2}\right)$; (iv) the combination of hydrogen peroxide with ultraviolet irradiation; (v) Fenton reactions, where the decomposition of hydrogen peroxide to the hydroxyl radical is achieved using $\mathrm{Fe}^{2+}$ as a catalyst; (vi) the photo-Fenton process, which combines the Fenton processes with ultraviolet irradiation; and (vii) solar photoelectron-Fenton process.

The hydroxyl radical interacts with organic ecules, resulting in the formation of organic radicals that, in turn, react with oxygen, giving rise to a number of degradation reactions in the final step of producing carbon dioxide, water, and some 
elements such as $\mathrm{S}, \mathrm{Cl}, \mathrm{P}, \mathrm{S}$, and $\mathrm{N}$, and some inorganic compounds are formed, for example $\mathrm{SO}_{2}, \mathrm{SO}_{3}$, and $\mathrm{NO}$ [12-18].

Hydrogen peroxide is one of the products of the oxygen reduction reaction (ORR), which includes some elementary steps in the reaction mechanism, and it can be used for the electrogeneration of the hydroxyl radical. Thus, for obtaining hydrogen peroxide in dilute acid, the ORR occurs by the transference of two electrons, and it is described following the equation below [18-23]:

$\mathrm{O}_{2}+2 \mathrm{H}^{+}+2 \overline{\mathrm{e}} \rightarrow \mathrm{H}_{2} \mathrm{O}_{2}$

In alkaline solution, the reaction is described in the following equation:

$\mathrm{O}_{2}+\mathrm{H}_{2} \mathrm{O}+2 \mathrm{e} \rightarrow \mathrm{HO}_{2}^{-}+\mathrm{OH}^{-}$

Equations (1) and (2) represent the hydroxide peroxide formation mechanism via two electrons, which are the steps of interest in the oxygen reduction process. However, oxygen reduction is a complex process because the reaction can occur according to Eqs. (1) and (2) or via the four-electron mechanism, in which the final product is water. The material used as an electrocatalyst determines the preferred pathway, wherein the carbon is taken as the reference material for hydrogen peroxide electrogeneration, which is of great interest in the degradation of organic pollutants [18-23].

Regarding the choice of the electrocatalysts, nanostructured materials (NMs) have showed promise for this purpose [9, 24], as they exhibit the following important properties: dispersion, quantum confinement effects, high surface area, and favorable chemical and structural characteristics, such as active sites and accessibility of the pore systems [24-26].

Among the main methods of thermal decomposition to produce NMs, one can point out the polymeric precursor method (PPM) [27-31] and the sol-gel method (SGM) [31-33].

Black carbon is used as a support for metal or metal oxide catalysts, such as vanadium oxide studied here. The use of this particular support is due to factors such as the sufficiently large and accessible surface area for maximum dispersion of crystallites, pore size, pore distribution, and the presence of suitable functional groups on the surface, which can be modified by covalently bonded organic functional groups or polymers [34, 35]. The grafting of surface groups or polymer chains changes the physicochemical properties of the particles, such as the dispensability, viscosity of the carbon suspension, and the surface energy, among others [35]. Due to the presence of oxygenated functional groups and the aromatic condensed rings on the surface of black carbon, it can act as a radical scavenger, significantly influencing the radical fixation or peroxide decomposition [36, 37].

In this context, it is well known that the addition of transition metals on carbon [19-23, 38-41] increases its activity for the generation of $\mathrm{H}_{2} \mathrm{O}_{2}[30,42,43]$. This activity depends on the type of oxygen adsorption on the metal surface supported on carbon. Three models can occur simultaneously on the surface of the electrocatalyst. In the Griffiths model (sideon), the oxygen ecule interacts laterally and leads to a strong interaction with the catalyst to the dissociation of the oxygen ecule, producing water. In the Pauling model (end-on), the oxygen ecule interacts with the electrocatalyst, even though this interaction does not break the oxygen-oxygen bond, favoring the formation of hydrogen peroxide as a final product. In the Bridge model, there is also a lateral interaction with the oxygen ecule; in contrast, colon adsorption occurs with the subsequent disruption of the bond between oxygen atoms, and water is the final product [44].

In the search for novel electrocatalyst systems used in ORR, the use of vanadium supported on black carbon produced for the PPM and SGM was chosen in this work [45, 46]. The mineral is very abundant in Brazil (Maracás mine, Bahia) and can be produced at reduced extracting costs [47].

Vanadium and related compounds have been studied and proved to have favorable properties regarding $\mathrm{H}_{2} \mathrm{O}_{2}$ electrogeneration $[45,46]$. The most stable compound of $\mathrm{V}_{2} \mathrm{O}_{5}$ has been shown to be very promising due to its interesting physical and chemical properties; the most beneficial properties include its stability, acidity, structure, and formation of layers that behave as a single-phase system due to the strong interactions at the oxide-water interface. Another important property is vanadium's incomplete $d$ orbital, which favors the formation of $\mathrm{V}_{2} \mathrm{O}_{5}$; the oxide possesses spaces between its connections, suggesting the increased adsorption of oxygen into its cavities, in a reversible manner according to the Pauling model, which promotes the reactions on the chemical surface [28, 45, 48, 49]. This suggests that in the formation of the vanadyl radical, several $\mathrm{V}_{2} \mathrm{O}_{5}$ ecules bind together, which increases the number of defects and contributes to oxygen adsorption [45]. It is also sensitive to the $\mathrm{pH}$ of the environment, similar to many catalytic reactions and electrochemical sensors. $\mathrm{V}_{2} \mathrm{O}_{5}$ can be produced in nanostructured form either by thermal evaporation or by the SGM. The latter method is widely used due to its simplicity and low synthesis temperature [49].

Therefore, vanadium oxide-based electrocatalysts supported on the carbon surface are considered very promising for use in AOPs, coupled with electrochemical methods for the treatment of organic water pollutants, as well as in the treatment of wastewater by fostering interest in microscale production of $\mathrm{H}_{2} \mathrm{O}_{2}$. Considering that no studies have considered vanadium on carbon $(\mathrm{V} / \mathrm{C})$ nanostructures prepared by both methods (PPM and SGM) and the quantity of reagents utilized in a previous study was different [46], this work will compare the influence of the preparation method on carbon modification using different vanadium ratios for peroxide electrogeneration electrocatalysts. 


\section{Experimental Procedure}

The V/C nanostructured electrocatalysts were prepared by two methods, PPM and SGM. The proportions of mass for metallic vanadium supported on carbon Vulcan XC 72R (Cabot Co.) in both methods were $1,3,5,7,10$, and $13 \%$.

\section{Preparation of the Electrocatalysts}

\section{Polymeric Precursor Method}

The electrocatalysts were prepared based on the method described by De Souza et al. [29, 50], which is related to the proportion of the reactants used to form the polymer network and uses 1 e of metallic vanadium (used $\mathrm{VCl}_{3}, 97 \%$, SigmaAldrich) for every 25 e of monohydrate citric acid ( $>99.0 \%$, Sigma-Aldrich) and 200 e of ethylene glycol (>99.0\%, Synth), i.e., a ratio of 1:25:200. Citric acid and ethylene glycol were mixed and used to form a polymeric network, which assists in the synthesis of the carbon and the metal under study, which, in this case, is vanadium. This mixture was held under agitation at a controlled temperature $\left(60{ }^{\circ} \mathrm{C}\right)$. Vanadium is added as vanadium(III) chloride, maintaining both the heating at $60{ }^{\circ} \mathrm{C}$ and stirring for $20 \mathrm{~min}$. Subsequently, $0.5 \mathrm{~g}$ of Vulcan XC 72R carbon was added and stirred in solution for 20 min without heating. The masses for vanadium in the samples are those ones for $1,3,5,7,10$, and $13 \%$ compared to carbon. The prepared materials were introduced into a furnace at a temperature of $400{ }^{\circ} \mathrm{C}$ for at least $2 \mathrm{~h}$ under a $\mathrm{N}_{2}$ atmosphere for calcination.

\section{Sol-Gel Method}

The electrocatalysts were prepared according to an adapted method of Santos et al. [51] and Suffredini et al. [52] using glacial acetic acid ( $>99.7 \%$, Synth) together with isopropyl alcohol ( $>99.5 \%$, Synth) to form a sol-gel resin with a proportion of 20:30, respectively, per gram of carbon. Sequentially, vanadium(III) chloride was added and, finally, $0.5 \mathrm{~g}$ of Vulcan $\mathrm{XC} 72 \mathrm{R}$ carbon was used to homogenize the resin in an ultrasound bath for $30 \mathrm{~min}$ after each addition. The masses for vanadium in the samples are those ones for $1,3,5,7,10$, and $13 \%$ compared to carbon. Subsequently, the sample was introduced into the furnace at a temperature of $400{ }^{\circ} \mathrm{C}$ for 15 min under a $\mathrm{N}_{2}$ atmosphere for calcination.

\section{Physical Chemical Characterization}

\section{Contact Angle Measurements}

The hydrophilicity of the V/C materials of PPM 7\%, SGM $3 \%$, and Vulcan XC 72R was studied using contact angle $(\theta)$ measurements (PixeLINK ${ }^{\circledR}$ Camera). According to Fig. 1, the material is hydrophilic for $\theta<90^{\circ}$ and hydrophobic for $\theta>90^{\circ}$.
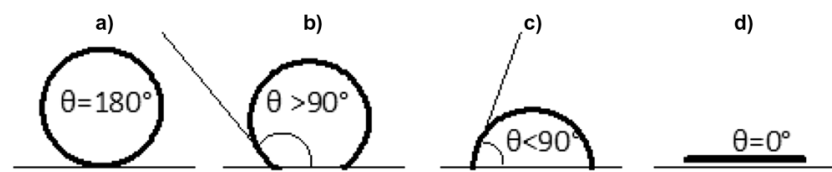

Fig. 1 Contact angles for liquids with solid surfaces. a Non-wetting. b Predominantly non-wetting. c Predominantly wetting. d Thoroughly wetting

An aliquot of the solution prepared for each sample was placed on a glassy carbon plate and dried by $\mathrm{N}_{2}$ flow. The glassy carbon plate was prepared with a dispersion device that added $5 \mu \mathrm{L}$ of water [53-55]. Immediately after the deposition of water, five measurements were taken, including an initial measurement followed by measurements at 1-min intervals.

\section{X-Ray Diffraction}

The V/C was characterized by an X-ray diffraction (XRD) technique using an X-ray diffractometer D8 Focus Bruker AXS with a $\mathrm{Cu} \mathrm{K} \alpha$ radiation source $(\lambda=1.5406 \AA)$, a $0.025^{\circ}$ increment ( $2 \mathrm{~s}$ per step) operated in continuous scan mode from $20^{\circ}$ to $80^{\circ}$, a voltage of $40 \mathrm{kV}$, and a $40 \mathrm{~mA}$ current. This analysis determined the presence of metal oxides and/or metals on the support surface using EVA software for XRD data analysis.

\section{Transmission Electron Microscopy}

The V/C PPM 7\% and SGM 3\% were characterized using the transmission electron microscope JEM-2100 model (200 kV). For the analysis, a suspension of each electrocatalyst was prepared in isopropyl alcohol $(1: 10 \mathrm{w} / \mathrm{v})$, where it was homogenized in an ultrasound system for approximately $10 \mathrm{~min}$. Subsequently, a sample aliquot was deposited on a copper grid ( $3 \mathrm{~mm}$ diameter) with a carbon film. These copper grids were placed in the sample holder of the transmission electron microscope.

\section{X-Ray Photoelectron Spectroscopy Measurements}

The X-ray photoelectron spectroscopy (XPS) analysis was conducted at a pressure of less than $10^{-7} \mathrm{~Pa}$ using a commercial spectrometer (UNI-SPECS WHV System). The Al K $\alpha$ line was used ( $h=1486.6 \mathrm{eV})$, and the analyzer pass energy was set to $10 \mathrm{eV}$. The inelastic background of the $\mathrm{V} 2 p, \mathrm{C} 1 s$, and $\mathrm{O} 1 s$ electron core-level spectra was subtracted using Shirley's method. The composition (in \%) of the nearsurface region was determined with an accuracy of $\pm 10 \%$ from the ratio of the relative peak areas corrected by Scofield's sensitivity factors of the corresponding elements. The spectra were fitted without placing constraints using multiple Voigt profiles. The full width at half maximum (FWHM) varied between 1.2 and $2.1 \mathrm{eV}$, and the accuracy of the peak positions was $\pm 0.1 \mathrm{eV}$. 


\section{Electrochemical Experiments}

The working electrode was prepared according to an adaptation of the method developed by Paulus et al. [56], dispersing $5 \mathrm{mg}$ of the electrocatalyst on the carbon support in $5 \mathrm{~mL}$ of water. The dispersion was homogenized in an ultrasound bath (Sanders SW2000FI) for $15 \mathrm{~min}$. After homogenization, an aliquot of $20 \mu \mathrm{L}$ of the solution was placed on a vitreous carbon disc of a rotating ring-disc electrode (RRDE) and dried with $\mathrm{N}_{2}$ flow. After drying the layer of the electrocatalyst support, $20 \mu \mathrm{L}$ of diluted Nafion solution in water $(1: 100 v / v)$ was added to the layer, which was again dried by $\mathrm{N}_{2}$ flow. After this preparation, the supporting electrolyte was first deoxygenated with $\mathrm{N}_{2}$ flow for $20 \mathrm{~min}$ and then oxygenated for $30 \mathrm{~min}$ with $\mathrm{O}_{2}$ flow, and the oxygen flow was maintained for the recording of the polarization curves. The curves were obtained by varying the rotation rate of the RRDE between 100 and $3600 \mathrm{rpm}$ (rotor of EDI101 and controlling unit speed of CTV101) and a scan rate of $5 \mathrm{mV} \mathrm{s}^{-1}$.

The materials were evaluated for their catalytic activity by ORR using $\mathrm{NaOH}\left(1 \mathrm{e} \mathrm{L}^{-1}\right)$ as the electrolyte and a threeelectrode system in a conventional electrochemical cell, comprising an RRDE, with a gold ring (area $=0.1866 \mathrm{~cm}^{2}$ ), a vitreous carbon disc (area $=0.2475 \mathrm{~cm}^{2}$ ), and an experimental collection factor of 0.28 (theoretical $=0.22$ ). In this work, an $\mathrm{Hg} / \mathrm{HgO}$ electrode was used as reference and a platinum (Pt, area $=2 \mathrm{~cm}^{2}$ ) electrode was used as auxiliary. Afterward, these materials had their physical characteristics evaluated by XRD, transmission electron microscopy (TEM), XPS, and contact angle measurements, as previously described.

\section{Results and Discussion}

\section{X-Ray Diffraction Analysis}

The XRD patterns in Fig. 2a, b show broad peaks, indicating that the materials synthesized using the PPM and SGM consist of two distinct amorphous phases, $\mathrm{V}_{2} \mathrm{O}_{5}$ (JCPDS 41-1426) and $\mathrm{VO}_{2}$ (JCPDS 81-2392), respectively. Additionally, it is possible to observe the changes in the carbon diffraction peak
(JCPDS 75-1621) when vanadium is present in the structure. According to Tang et al. [57], when the vanadium concentration is below $10 \%$, the absence of any standard crystalline peaks of vanadium oxide indicates that these vanadium oxide nanoparticles are highly dispersed on the surfaces of carbon, as suggested by the peaks at $2 \theta$ of $30^{\circ}, 34^{\circ}$, and $49^{\circ}$ of $\mathrm{V}_{2} \mathrm{O}_{5}$. For both catalysts, the broad overlapping peaks suggest the existence of nanometer particles with amorphous character.

Figure 2 a shows enlarged peaks identified at $28^{\circ}$, indicative of $\mathrm{VO}_{2}$ phase intensity with carbon also present, where $2 \theta=37^{\circ}$ for all vanadium proportions, and narrow peaks at $56^{\circ}$ for the sample with $13 \%$ vanadium in carbon in Vulcan $\mathrm{XC} 72 \mathrm{R}$. For $\mathrm{V}_{2} \mathrm{O}_{5}$, the peaks at $26^{\circ}, 31^{\circ}, 34^{\circ}$, and $46^{\circ}$ showed reduced intensity, suggesting amorphous vanadium oxide phase. The appearance of these XRD peaks is assigned to the vanadium oxide layer formed on the carbon support $[46,57]$ showing amorphous phase, changing the initial characteristics of the peaks; these characteristics are due to carbon, which shows large peaks at $28^{\circ}$ and $36^{\circ}$.

In Fig. $2 \mathrm{~b}$ for all the catalysts, it is possible to see two enlarged peaks; probably, the phases present are not crystalline as expected for $\mathrm{VO}_{2}$ at $28^{\circ}$ and $37^{\circ}$ for all vanadium proportions for the material prepared by the SGM.

Although for $\mathrm{V}_{2} \mathrm{O}_{5}$ we suggest the presence of a peak at $26^{\circ}$ for the electrocatalyst containing $7 \%$ vanadium in Vulcan $\mathrm{XC} 72 \mathrm{R}$ and at $31^{\circ}, 34^{\circ}, 46^{\circ}$, and $51^{\circ}$ for vanadium at all proportions, with the most intense peak at $34^{\circ}$, these peaks present enlarged features related to amorphous phases. During carbon formation, a characteristic peak at $28^{\circ}$ [46] was observed, suggesting the insertion of the vanadium on the surface of Vulcan XC 72R by the SGM modified the carbon surface for all proportions added, with a peak first observed for $\mathrm{V} / \mathrm{C} 7 \%$ at $26^{\circ}$, which is a characteristic of $\mathrm{V}_{2} \mathrm{O}_{5}$.

$\mathrm{XRD}$ indicates that the main oxide phase of electrocatalysts formed in both preparation methods is probably $\mathrm{V}_{2} \mathrm{O}_{5}$. This oxide has an acidic nature $[28,46,58]$, and the acidic surface shows a higher affinity due to the presence of hydroxyls $(\mathrm{OH})[46,59]$. This feature could increase the hydrophilicity of the V/C nanostructured electrocatalysts produced by the PPM and SGM, thereby increasing the catalytic activity in ORR [23, 46] and leading to the increased production of electrogenerated $\mathrm{H}_{2} \mathrm{O}_{2}$.
Fig. 2 XRD patterns of vanadium oxide nanoparticles present at different proportions $(w / w)$ on carbon, prepared by the PPM (a) and SGM (b)
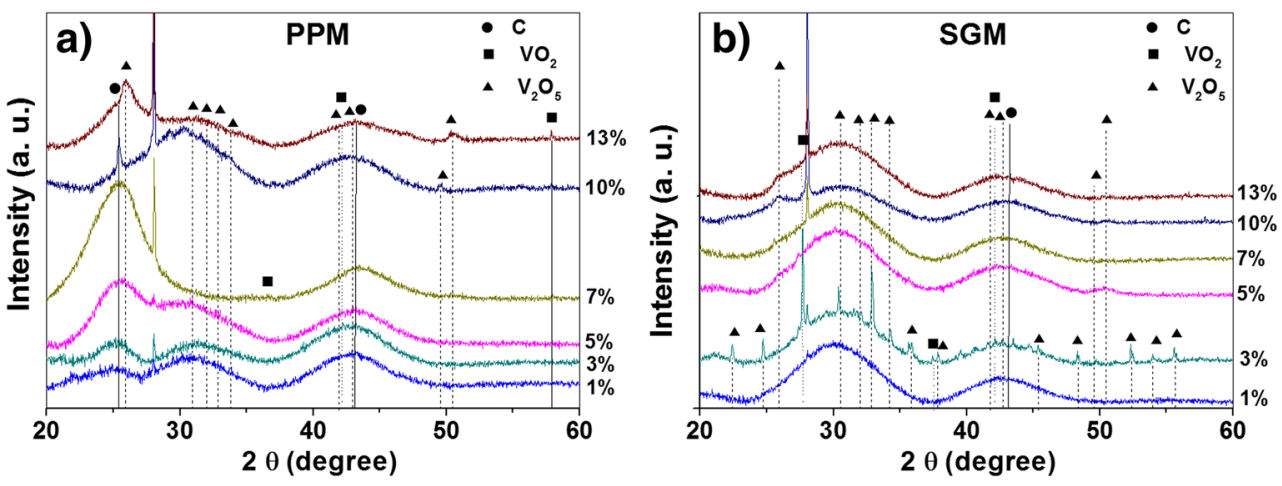


\section{Transmission Electron Microscopy Characterization}

Because the V/C PPM 7\% and SGM 3\% materials showed the most promising results for peroxide electrogeneration (see results using the rotating ring-disc technique), they were analyzed by TEM. Figure 3 shows some morphological characteristics of vanadium oxide nanoparticles on the carbon surface in the size range between 5 and $20 \mathrm{~nm}$.

A low metallic load is evident in all images, showing areas where we have metal particles anchored onto the carbon support (dots). The nanometric metal dots show a clustering tendency for a PPM 7\% material. There are areas with a high carbon support agglomeration on PPM materials, probably due to the heat treatment (the starting resin is more viscous in the case of PPM than in SGM). It is not possible to observe the formation of fringes due to particle size.

\section{XPS Analysis}

The composition of the catalysts was derived by the quantitative XPS analysis. As expected, the obtained vanadium atomic percentages were 1.5 and 0.5 at.\% for the nominal concentrations of V/C PPM 7\% and V/C SGM 3\%, respectively. For the catalyst prepared by the SGM, a higher oxygen concentration was detected, indicating more oxygenated groups present on this carbon support. The obtained atomic concentrations were 90.8 at.\% $\mathrm{C}$ and 7.7 at.\% $\mathrm{O}$ for the V/C PPM 7\% and 88.5 at.\%
$\mathrm{C}$ and 11.0 at.\% O for the V/C SGM 3\% catalyst. The chemical shifts of the core-level components were due to the functional groups of carbon and the oxidation state of vanadium.

Information on the local bonding structure was obtained by the deconvolution of the carbon (C) $1 s$, oxygen (O) $1 s$, and vanadium (V) $2 p_{3 / 2}$ high-resolution core-level spectra shown in Fig. 4. The low binding energy component of the $\mathrm{C} 1 \mathrm{~s}$ spectra, located at $284.5 \mathrm{eV}$, is related to graphitic carbon. The sub-peak at approximately $285.2 \mathrm{eV}$ was assigned to aliphatic hydrocarbons, mostly $\mathrm{sp}^{3} \mathrm{C}$, present in the amorphous structure of the nanoparticulated material. The components forming the high-energy tail are related to the $\mathrm{C}-\mathrm{O}, \mathrm{C}=\mathrm{O}$, and $\mathrm{O}-\mathrm{C}=\mathrm{O}$ groups observed at 286.4, 287.7, and $289.3 \mathrm{eV}$, respectively. The high-binding energy component centered at approximately $291.0 \mathrm{eV}$ is related to photoemission-induced plasmonic $\pi \rightarrow \pi^{*}$ transitions. Based on the intensity of the aromatic $\mathrm{C}-\mathrm{C}$ component, the latter is a measure of the degree of aromaticity of the carbon structure.

From the C $1 s$ spectra in Fig. 4, it is evident that the catalyst support of the SGM presents a more oxygenated group than that of the PPM support, which predominantly presents an aromatic carbon structure.

The fitted $\mathrm{O} 1 \mathrm{~s}$ core-level spectra are similar for all samples (Fig. 4). Four components, located at 530.2, 531.8, 532.5, and $533.8 \mathrm{eV}$, are related to the $\mathrm{O}-\mathrm{V},-\mathrm{OH}^{-} / \mathrm{O}=\mathrm{C}, \mathrm{O}-\mathrm{C}$, and $\mathrm{O}-$ $\mathrm{C}=\mathrm{O}$ groups, respectively. As expected, for the V/C PPM 7\% sample, the proportion of the $\mathrm{O}-\mathrm{V}$ component scales with the
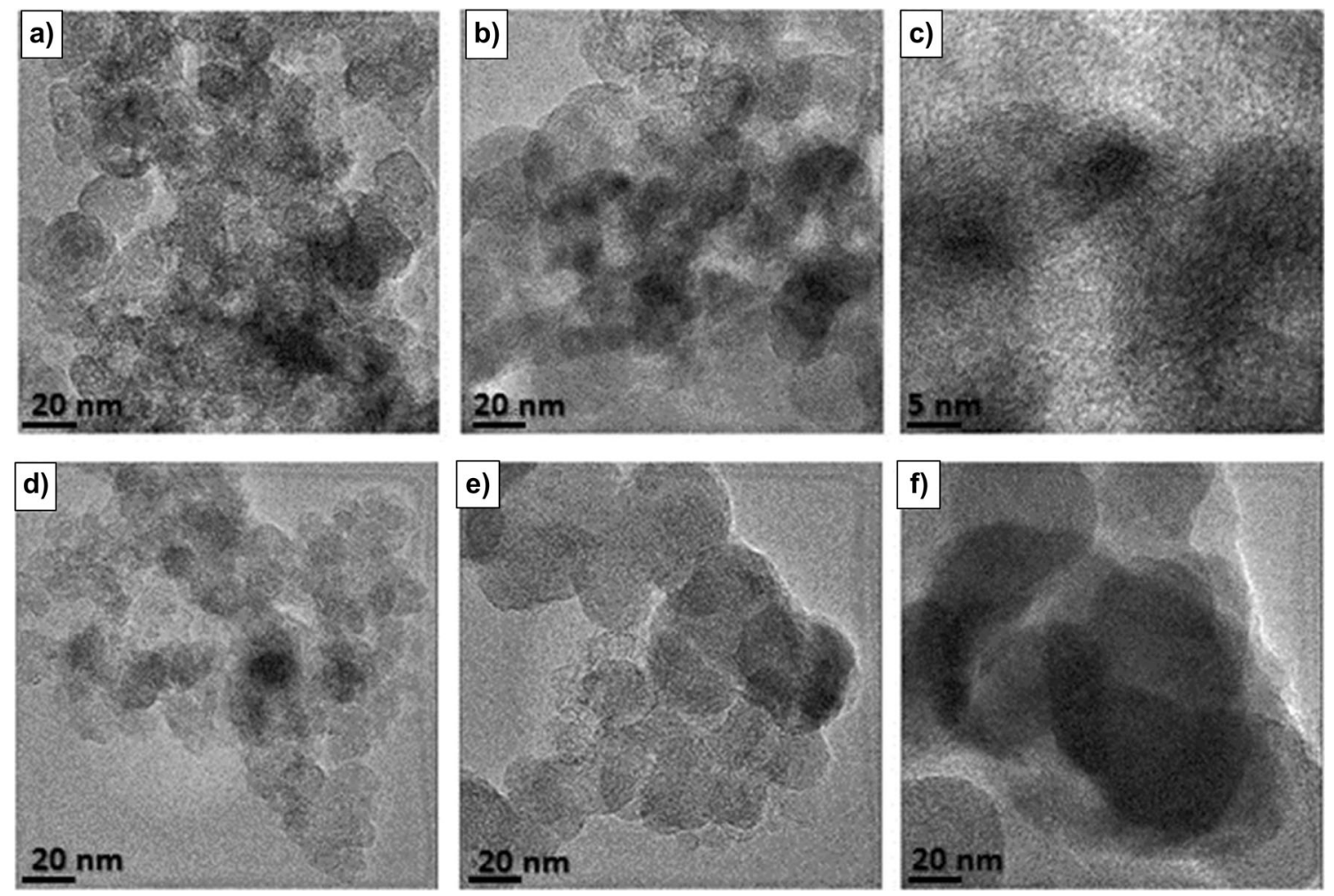

Fig. 3 TEM images of the a-c V/C PPM 7\% and d-f V/C SGM $3 \%$ electrocatalysts 
Fig. 4 XPS C $1 s, \mathrm{O} 1 s$, and $\mathrm{V}$ $2 p_{3 / 2}$ spectra of a V/C PPM $7 \%$ and $\mathbf{b}$ V/C SGM $3 \%$. Circles are the experimental results
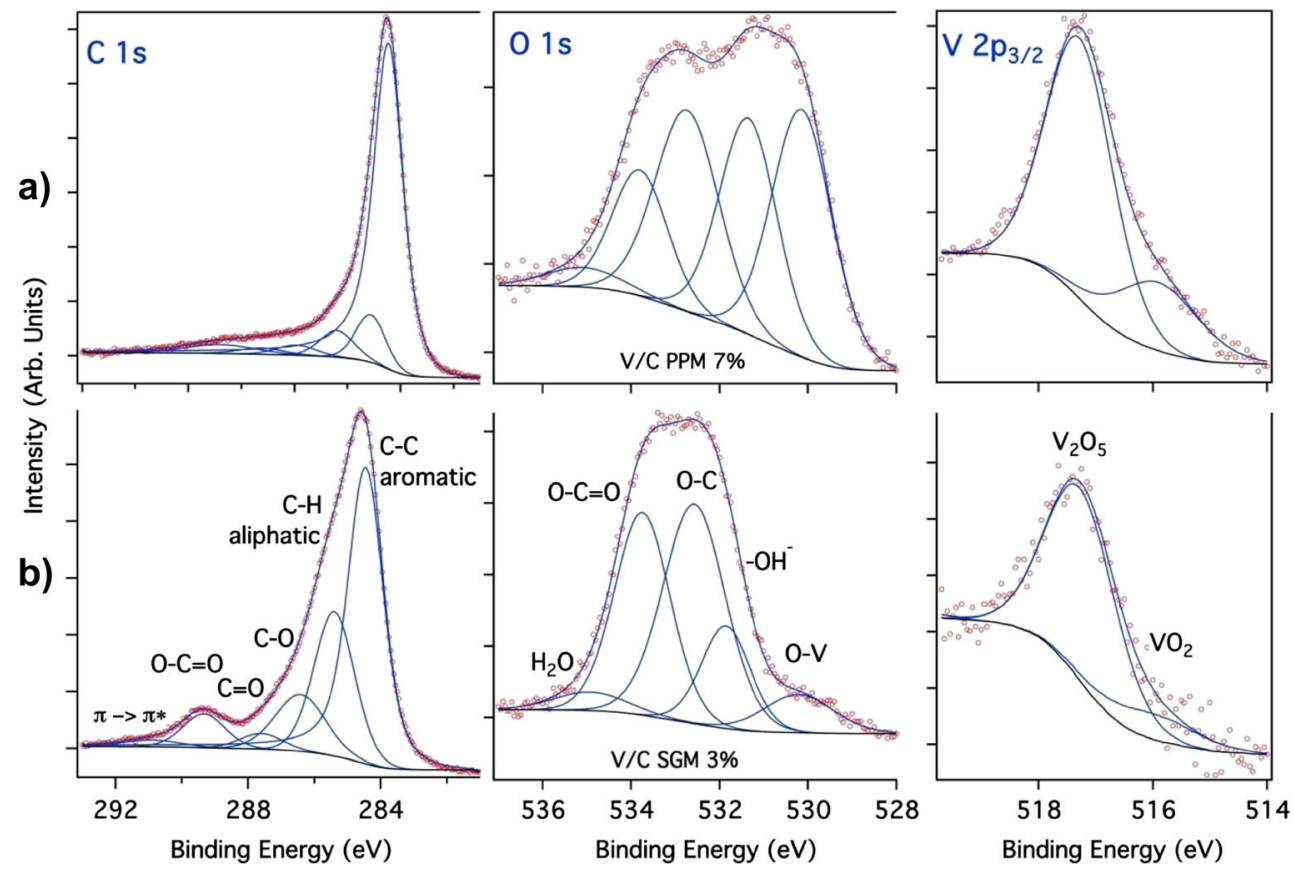

higher vanadium and lower oxygen content. Furthermore, it is interesting to note that for this sample, a higher contribution of vanadium hydroxyl surface groups was found, suggesting a more hydrophilic character of the surface. Alternatively, the analysis of the $\mathrm{C} 1 s$ spectrum of V/C SGM $3 \%$ showed a more oxidized carbon surface, which might favor the catalytic activity of this material.

The $\mathrm{V} 2 p_{3 / 2}$ spectra confirmed the XRD data, showing that the $\mathrm{V}_{2} \mathrm{O}_{5}$ is the predominant vanadium phase (Fig. 4), with $\mathrm{VO}_{2}$ observed only in the case of V/C PPM 7\%. The acidic nature of the $\mathrm{V}_{2} \mathrm{O}_{5}$ phase combined with the presence of oxidized carbon sites should have a synergetic effect on the efficiency of the ORR.

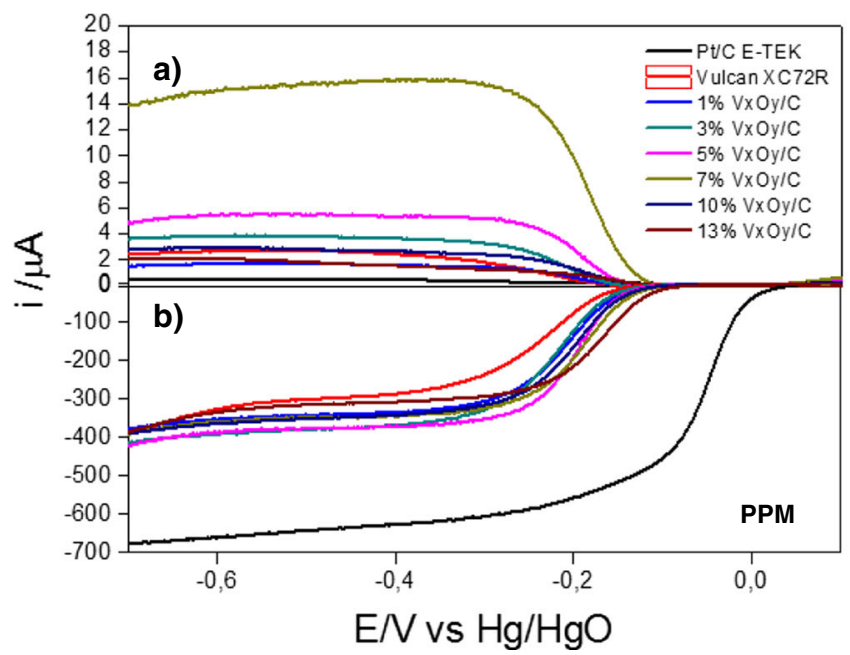

Fig. 5 Steady-state polarization curves for the ORR on different proportions of vanadium oxide materials supported on carbon prepared by the PPM (a, b), SGM (c, d), Vulcan XC 72R, and Pt/C E-TEK in

\section{Electrochemical Characterization}

The results of the polarization curves provide graphs evaluating the possible materials that generate a great amount of hydrogen peroxide [60-62] as well as the tendency to follow the ORR through two-electron or four-electron pathways [19-23].

The electrocatalytic activity of these $\mathrm{V} / \mathrm{C}$ electrocatalysts is related to the production of $\mathrm{H}_{2} \mathrm{O}_{2}$ from ORR [19-23], which was evaluated using the RRDE technique. Figure 5 shows the polarization curves using combinations of $\mathrm{V} / \mathrm{C}$ mass percentages of 1, 3, 5, 7, 10, and 13\%; Vulcan XC 72R; and platinum (Pt/C E-TEK). The ORR using Pt/C E-TEK as an electrocatalyst showed the highest current for the reaction

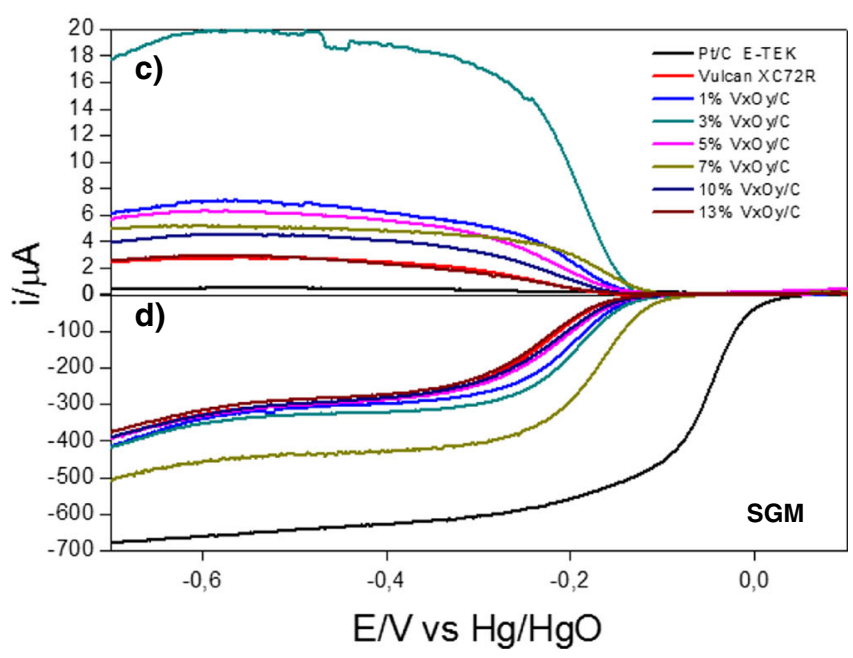

oxygen-saturated $1 \mathrm{e} \mathrm{L}^{-1} \mathrm{NaOH}$ at a scan rate of $5 \mathrm{mV} \mathrm{s}^{-1}$. a PPM and $\mathbf{c}$ SGM with the ring held at $0.2 \mathrm{~V}$ during the potential scan at the disc. $\mathbf{b}$ PPM and d SGM disc current at $1600 \mathrm{rpm}$ 

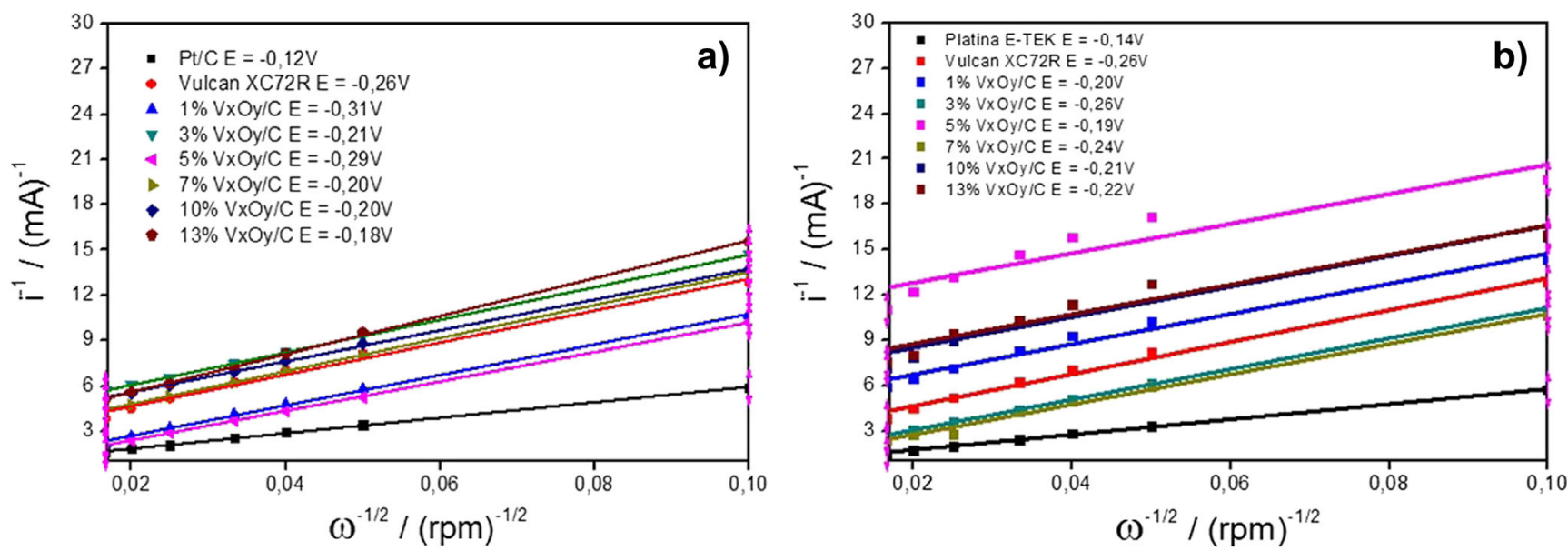

Fig. 6 Koutecky-Levich plot for ORR of vanadium oxide materials prepared by the a PPM and b SGM. Vulcan XC 72R and Pt/C E-TEK were used for comparison

(Fig. 5b, d) compared to the other materials tested; this material is well known as a reference for four-electron transference during ORR, with $\mathrm{H}_{2} \mathrm{O}$ electrogeneration [19-23].

Taking into account Fig. 5a, the V/C nanostructures prepared by the PPM $[29,50]$, i.e., V/C 3\% and V/C 7\%, presented high ring currents, particularly the $\mathrm{V} / \mathrm{C} 7 \%$ electrocatalyst, which presented a current approximately five times greater than that associated with carbon for peroxide production.

In Fig. 5c, the vanadium-based electrocatalyst supported on V/C 3\% prepared by the SGM [51, 52] presented a ring current $\left(\mathrm{H}_{2} \mathrm{O}_{2}\right.$ electrogeneration) seven times higher than that for the same process on Vulcan XC 72R.

The results presented in Fig. 5 show the behavior of the $\mathrm{V} / \mathrm{C}$ electrocatalysts in regard to the ORR, which was either equal to or better than that of Vulcan $\mathrm{XC}$ $72 \mathrm{R} \mathrm{H}_{2} \mathrm{O}_{2}$ electrogeneration. $\mathrm{V} / \mathrm{C}$ PPM $7 \%$ and $\mathrm{V} / \mathrm{C}$ SGM 3\% exhibit the highest percentages of $\mathrm{H}_{2} \mathrm{O}_{2}$ electrogeneration.

The results of the polarization curve for all materials shown in Fig. 5 were also analyzed with the Koutecky-Levich plot in Fig. 6a, b. It is possible to observe that the slope of the straight lines concerning ORR for $\mathrm{V} / \mathrm{C}$ materials prepared by both the PPM and SGM was similar to that of carbon, which is a reference material for $\mathrm{H}_{2} \mathrm{O}_{2}$ production by two electrons from ORR, different from the result observed for the Pt/C E-TEK, which is the reference material for the production of $\mathrm{H}_{2} \mathrm{O}$ via four electrons [23, 30, 61].

These plots are the result of the Koutecky-Levich (K-L) equation (Eq. (3)) [23, 30, 60] described below, which explains the observed slopes in Fig. 6, and the results of these inclinations are described in Table 1:

$\frac{1}{i}=\frac{1}{i_{\mathrm{k}}}+\frac{1}{i_{\mathrm{dl}}}=\frac{1}{\mathrm{nFkC}_{\mathrm{O}_{2}}}+\frac{1}{0.2 \mathrm{nFAD}_{\mathrm{O}_{2}}^{3 / 2} v^{-1 / 6} C_{\mathrm{O}_{2}} \omega^{1 / 2}}$

where $i_{\mathrm{k}}$ is the kinetic current, $i_{\mathrm{dl}}$ is the diffusional current, $n$ is the number of electrons transferred in the ORR, $F$ is the Faraday constant, $A$ is the geometric area of the disc electrode, $C_{\mathrm{O}_{2}}$ is the concentration of dissolved oxygen in the electrolyte, oxygen $D_{\mathrm{O}_{2}}$ is the diffusion coefficient, $\nu$ is the kinematic viscosity of the electrolyte, $\omega$ is the electrode rotational rate, and $k$ is a constant for ORR.

In Table 1, the value obtained for Vulcan XC 72R was 106. Similar values were presented by V/C produced by the PPM and SGM, which showed slopes of 98 and 126, respectively. For the V/C PPM 7\% electrocatalyst, this value was 110, whereas for the V/C SGM 3\% electrocatalyst, the value was 101. These values are similar to those measured for Vulcan XC 72R, which suggests a catalytic activity by two electrons in the ORR mechanism for both electrocatalysts. The Pt/C ETEK presented a slope of 58 . However, the vanadium percentage used in the PPM was two times higher than that used in the SGM. Thus, from an economic point of view, the V/C SGM $3 \%$ can be considered as more promising for the $\mathrm{ORR}$ in $\mathrm{H}_{2} \mathrm{O}_{2}$ electrogeneration among the tested materials. We suggest that these results can be associated with the species formed on the

Table 1 Inclinations obtained from the Koutecky-Levich plots in the V/C electrocatalysts prepared by the PPM and SGM. Pt/C E-TEK and Vulcan XC $72 \mathrm{R}$ were used for comparison

\begin{tabular}{|c|c|c|c|c|c|c|c|c|}
\hline Electrocatalyst & Pt/C E-TEK & Vulcan XC 72R & $1 \% \mathrm{~V} / \mathrm{C}$ & $3 \% \mathrm{~V} / \mathrm{C}$ & $5 \% \mathrm{~V} / \mathrm{C}$ & $7 \% \mathrm{~V} / \mathrm{C}$ & $10 \% \mathrm{~V} / \mathrm{C}$ & $13 \% \mathrm{~V} / \mathrm{C}$ \\
\hline PPM & 51 & 106 & 101 & 108 & 98 & 110 & 102 & 126 \\
\hline SGM & & & 100 & 101 & 98 & 100 & 101 & 98 \\
\hline
\end{tabular}


carbon surface due to the anchoring vanadium [32, 46, 48, 49] and the consequent surface modification of the electrocatalyst, as previously observed in both the XRD results and XPS measurements.

\section{Characterization by Contact Angle}

The V/C PPM 7\% and V/C SGM 3\% materials subjected to the contact angle test for hydrophilicity evaluation show an alteration of the carbon surface with respect to wettability, with lower contact angle values than those obtained for Vulcan XC 72R. The average contact angle is calculated based on the angle of separation between the solid surface and the gas surface, which are separated by the substrate, in which case, the catalysts are water droplets, with both the left side and the right side of the droplet, as observed from the equipment [53-55].

As the contact of the solid surface of the droplet has a total angle of $180^{\circ}$, the wettability is the difference between this angle $\left(180^{\circ}\right)$ and the measured angle based on the tangent $(\theta)$, as described in Eq. (7)

Wettability $=180-\theta$

The Vulcan XC 72R carbon had an average contact angle of $58.4^{\circ}$, which represents a $121.6^{\circ}$ wettability. The V/C PPM $7 \%$ sample had an average contact angle of $19.9^{\circ}$, which represents a wettability of $160.12^{\circ}$, whereas the V/C SGM $3 \%$ sample had an average contact angle of $21.8^{\circ}$, which represents a $158.2^{\circ}$ wettability. The wettability values for electrocatalysts were very similar, but they were higher than the values determined for the Vulcan XC 72R, indicating that the addition of the vanadium metal on the carbon support has changed its surface and that this is one factor that contributes to the adsorption of oxygen and its transformation into $\mathrm{H}_{2} \mathrm{O}_{2}$ due to the increasing hydrophilicity of the surface.

\section{Conclusions}

Based on the results obtained for the vanadium-based nanostructured electrocatalysts supported on carbon, the V/C PPM $7 \%$ and V/C SGM $3 \%$ presented results significantly better than those obtained for pure Vulcan XC 72R carbon regarding the currents obtained for rotating ring-disc experiments toward peroxide electrogeneration.

The results obtained by $\mathrm{X}$-ray diffraction showed the preferential formation of the $\mathrm{V}_{2} \mathrm{O}_{5}$ phase for both preparation methods. $\mathrm{V}_{2} \mathrm{O}_{5}$ has an acidic nature, favoring the formation of $\mathrm{H}_{2} \mathrm{O}_{2}$, due to the affinity for containing hydroxyl species. $\mathrm{X}$-ray photoelectron spectroscopy (XPS) confirmed these results, showing the predominance of the $\mathrm{V}_{2} \mathrm{O}_{5}$ phase and the presence of hydroxyl surface groups for samples with the highest catalytic activity and for the V/C SGM 3\% catalyst, a highly oxidized carbon support, which favors the ORR. The TEM images suggest the formation of sub-microscopic V/C particles and amorphization of electrocatalysts, confirming the measurements in the diffraction patterns regarding the characteristics of the formed phases.

The contact angle measurements showed that the surface modification of carbon in the presence of vanadium can contribute to the increased catalytic activity of these electrocatalysts. The V/C PPM 7\% and V/C SGM 3\% electrocatalysts exhibited highly hydrophilic surfaces, with contact angles of $19.9^{\circ}$ and $21.8^{\circ}$, respectively, which are significantly lower than the contact angle obtained for the pure Vulcan XC 72R support (58.4 $)$.

The results showed that increasing the proportion of vanadium anchored to the carbon surface does not result in increased catalytic activity for the $\mathrm{H}_{2} \mathrm{O}_{2}$ electrogeneration. Concerning the different methodologies for anchoring the vanadium on the carbon surface, the findings showed that different proportions of the metal supported on carbon provides similar results, mainly due to the different surface modifications of the carbon support. However, from an economic point of view, the V/C SGM 3\% can be considered as more promising for the $\mathrm{ORR}$ in $\mathrm{H}_{2} \mathrm{O}_{2}$ electrogeneration among the tested materials

Acknowledgements The authors wish to thank the Central de Análises Químicas Instrumentais of Instituto de Química de São Carlos (CAQI/IQSC/USP), IPEN, for the TEM measurements and the Brazilian funding institutions, CNPq (577292/2008-0, 473308/2010-0), CAPES and FAPESP (2005/59992-6, 2008/58789-0, 2009/09145-6, 2010/04539-3, 2010/16511-6, 2007/04759-0, 2011/00002-8, 2011/21656-6, 2015/10314-8), and UFABC, for their financial support.

\section{References}

1. R.F.P. Nogueira, A.G. Trovó, M.R.A. Silva, R.D. Villa, Fundamentals and applications of environmental processes and photo-Fenton Fenton. Química Nova 30(2), 400-408 (2007)

2. M. Skoumal, P.L. Cabot, F. Centellas, C. Arias, R.M. Rodriguez, J.A. Garrido, E. Brillas, Mineralization of paracetamol by ozonation catalyzed with $\mathrm{Fe}^{2+}, \mathrm{Cu}^{2+}$ and UVA light. Appl. Catal. B Environ. 66, 228-240 (2006)

3. F.E. Wania, D. Mackay, Global distillation. Unep Nairobi 8, 15-16 (1997)

4. R.S. Freire, R. Pelegrini, L.T. Kubota, N. Durán, P. Peralta-Zamora, New trends for treatment of industrial effluents containing organochloride species. Química Nova 23(4), 504-511 (2000)

5. Demajorovic J. Society of risk and environmental responsibility: prospects for corporate education. São Paulo. Senac São Paulo. 2001

6. F.F. Felix, S. Navickiene, H.S. Dórea, Persistent organic pollutants (POPS) as soil quality indicators. Fapese Magazine 3(2), 39-62 (2007)

7. M.M. Kondo, W.F. Jardim, Photodegradation of chloroform and urea using Ag-loaded titanium dioxide as catalyst. Water Res. 25(7), 823-827 (1991) 
8. R. Andreozzi, V. Caprio, A. Insola, R. Marotta, R. Sanchirico, Advanced oxidation processes for the treatment of mineral oilcontaminated wastewaters. Water Res. 34, 620-628 (2000)

9. X. Qu, P.J.J. Alvarez, Q. Li, Applications of nanotechnology in water and wastewater treatment. Water Res. 47, 3931-3946 (2013)

10. D.M. Bila, M. Dezotti, Drugs in the environment. Química Nova 26(4), 523-530 (2003)

11. M.N. Chong, B. Kin, C.W.K. Chow, C. Saint, Recent developments in photocatalytic water treatmente technology: a review. Water Res. 44, 2997-3027 (2010)

12. H. Hidaka, S. Yamada, S. Suenaga, H. Kubota, N. Serpone, E. Pelizzetti, M. Grätzel, Photodegradation of surfactants. V. Photocatalytic degradation of surfactants in the presence of semiconductor particles by solar exposure. J. Photochem. Photobiol. A Chem. 47, 103-112 (1989)

13. M.-C. Lu, G.-D. Roam, J.-N. Chen, C.P. Huang, Photocatalytic mineralization of toxic chemicals with illuminated $\mathrm{TiO} 2$. Chem. Eng. Commun. 139, 1-13 (1995)

14. S.L. Woods, J.F. Ferguson, M.M. Benjamin, Characterization of chlorophenol and chloromethoxybenzene biodegradation during anaerobic treatment. Environ Sci Technol 23, 62-68 (1989)

15. V. Augugliaro, L. Palmisano, M. Schiavello, A. Sclafani, L. Marchese, G. Martra, F. Milano, Photocatalytic degradation of nitrophenols in aqueous titanium dioxide dispersion. Appl. Catal. 69, 323-340 (1991)

16. G. Mininni, A. Sbrilli, E. Guerriero, M. Rotatori, Dioxins and furans formation in pilot incineration tests of sewage sludge spiked with organic chlorine. Chemosphere 54, 1337-1350 (2004)

17. K. Rajeshwar, J. Ibañez, Fundamentals and applications in pollution abatement, environmental electrochemistry (Academic, Cambridge, 1997), pp. 1-737

18. C.A.R. Ragnini, R.A. Di Iglia, R. Bertazzoli, Considerations about electrogeneration of hydrogen peroxide. Química Nova 24, 252$256(2001)$

19. M. Giomo, A. Buso, P. Fier, G. Sandona, B. Boye, G. Farnia, A small-scale pilot plant using an oxygen-reducing gas-diffusion electrode for hydrogen peroxide electrosynthesis. Electrochim. Acta 54, 808-815 (2008)

20. P. Drogui, S. Elmaleh, M. Rumeau, C. Bernard, A. Rambaud, Hydrogen peroxide production by water electrolysis: application to disinfection. J Appl Electroch 31, 877-882 (2001)

21. J. Gonzales-Garcia, C.E. Banks, R.G. Compton, Electrosynthesis of hydrogen peroxide via the reduction of oxygen assisted by power ultrasound. Ultrason. Sonochem. 14, 405-412 (2007)

22. F. Alcaide, E. Brillas, P.L. Cabot, Impedance study of the evolution of a $\mathrm{HO} 2$ - - generating hydrophobic gas diffusion electrode. Electrochem. Commun. 4, 838-843 (2002)

23. M.H.M.T. Assumpção, R.F.B. De Souza, D.C. Rascio, J.C.M. Silva, M.L. Calegaro, I. Gaubeur, T.R.L.C. Paixão, P. Hammer, M.R.V. Lanza, M.C. Santos, A comparative study of the electrogeneration of hydrogen peroxide using Vulcan and Printex carbon supports. Carbon 49, 2842-2851 (2011)

24. E. Brillas, R.M. Batista, E. Llosa, Electrochemical destruction of aniline and 4- chloroaniline for wastewater treatment using a carbon-PTFE O2-fed cathode. J. Electrochem. Soc. 142, 1733$1741(1995)$

25. S.P. Ringer, K.R. Ratinac, On the role of characterization in the design of interfaces in nanoscale materials technology. Microsc. Microanal. 10, 324-335 (2004)

26. L. Seravalli, P. Frigeri, P. Allegri, V. Avanzini, S. Franchi, Metamorphic quantum dot nanostructures for long wavelength operation with enhanced emission efficiency. Mater. Sci. Eng. 27, 1046-1051 (2007)

27. J.C.M. Silva, L.S. Parreira, R.F.B. De Souza, M.L. Calegaro, E.V. Spinacé, A.O. Neto, M.C. Santos, PtSn/C alloyed and non-alloyed materials: differences in the ethanol electro-oxidation reaction pathways. Appl. Catal. B Environ. 110, 141-147 (2011)

28. R.F.B. De Souza, L.S. Parreira, J.C.M. Silva, F.C. Simões, M.L. Calegaro, M.J. Giz, G.A. Camara, A.O. Neto, M.C. Santos, $\mathrm{PtSnCe} / \mathrm{C}$ electrocatalysts for ethanol oxidation: DEFC and FTIR "in-situ" studies. I J Hydrog Energy 3611, 519-11527 (2011)

29. R.F.B. De Souza, A.E.A. Flausino, D.C. Rascio, R.T.S. Oliveira, E.T. Neto, M.L. Calegaro, M.C. Santos, Ethanol oxidation reaction on $\mathrm{PtCeO} 2 / \mathrm{C}$ electrocatalysts prepared by the polymeric precursor method. Appl. Catal. B; Environmental 91, 516-523 (2009)

30. M.H.M.T. Assumpção, A. Moraes, R.F.B. De Souza, I. Gaubeur, R.T.S. Oliveira, V.S. Antonin, G.R.P. Malpass, R.S. Rocha, M.L. Calegaro, M.R.V. Lanza, M.C. Santos, Low content cerium oxide nanoparticles on carbon for hydrogen peroxide electrosynthesis. Appl. Catal. A Gen. 411/412, 1-6 (2012)

31. Morais EA. Er incorporation into $\mathrm{SnO} 2$ obtained by sol-gel: a xerogels analysis and thin films. São Carlos, Universidade de São Paulo, Master thesis, 2002.

32. C. B. Rodella Preparation and characterization of V2O5 catalysts supported on TiO2. Universidade de São Paulo, São Carlos, Master thesis, 2001

33. R.S. Hiratsuka, C.V. Santilli, S.H. Pulcinelli, The sol-gel process: a physical-chemical vision—review. Química Nova 18(2), 171-179 (1995)

34. Villanueva AEL, Production of carbon nanostructured phases from the high pressure pyrolysis of carbonaceous precursors dispersed on inert matrices. Porto Alegre, Universidade Federal do Rio Grande do Sul, Phd thesis, 2012.

35. M. Carmo, Preparation, characterization and evaluation functionalized carbon for applications in PEM fuel cells (IPEN-Autarchy associated with the Universidade de São Paulo, São Paulo, 2008)

36. M.L. Studebaker, The chemistry of carbon black and reinforcement. Rubber Chemistry and Techology 30, 1400-1483 (1957)

37. Lopes CN, Synthesis and characterization of composite polystyrene/graphite produced through polymerization process suspended in situ. Florianópolis, Universidade Federal de Santa Catarina, Phd thesis, 2007.

38. J.C. Forti, R.S. Rocha, M.R.V. Lanza, R. Bertazzoli, Electrochemical synthesis of hydrogen peroxide on oxygen-fed graphite/PTFE electrodes modified by 2-ethylanthraquinone. J. Electroanal. Chem. 601, 63-67 (2007)

39. A.A.G.F. Beati, R.S. Rocha, J.G. Oliveira, M.R.V. Lanza, Study of the ranitidine degradation by $\mathrm{H} 2 \mathrm{O} 2$ electrogenerated/Fenton in an electrochemical reactor with gas diffusion electrode. Quim Nova 32(1), 125-130 (2009)

40. J.C. Forti, C.E. Venancio, M.R.V. Lanza, R. Bertazzoli, Effects of the modification of gas diffusion electrodes by organic redox catalysts for hydrogen peroxide electrosynthesis. J. Braz. Chem. Soc. 19, 643-650 (2008)

41. Beati AAGF, Study of ranitidine degradation via $\mathrm{H} 2 \mathrm{O} 2$ electrogenerated/Fenton in an electrochemical reactor with gas diffusion electrodes. Campinas, Universidade Estadual de Campinas, Master thesis, 2007.

42. R.S. Rocha, R.M. Reis, A.A.G.F. Beati, M.R. Lanza, M.D.P.T. Sotomayor, R. Bertazzoli, Development and evaluation of gas diffusion electrodes (GDE) for generation of $\mathrm{H} 2 \mathrm{O} 2$ in situ and their application in the degradation of reactive blue 19 dye. Química Nova 35(10), 1961-1966 (2012)

43. M.H.M.T. Assumpção, A. Moraes, R.F.B. De Souza, R.M. Reis, R.S. Rocha, I. Gaubeur, M.L. Calegaro, P. Hammer, M.R.V. Lanza, M.C. Santos, Degradation of dipyrone via advanced oxidation processes using a cerium nanostructured electrocatalyst material. Appl. Catal. A Gen. 462/463, 256-261 (2013)

44. Sousa NS, Study of the oxygen reduction reaction catalyzed by complex tetraazamacrociclos with different metal centers: a 
theoretical approach. São Luis, Universidade Federal do Maranhão, Master thesis, 2013.

45. S. Surnev, M.G. Ramsey, F.P. Netzer, Review: Vanadium oxide surface studies. Prog. Surf. Sci. 73, 117-165 (2003)

46. A. Moraes, M.H.M.T. Assumpção, R. Papai, I. Gaubeur, R.S. Rocha, R.M. Reis, M.L. Calegaro, M.R.V. Lanza, M.C. Santos, Use of a vanadium nanostructured material for hydrogen peroxide electrogeneration. J. Electroanal. Chem. 719, 127-132 (2014)

47. Moreira L, Costa V, Young J, Magazine ores and minerals; vanadium: Brazil Featured assumed position at the producers ranking; year XXXVIII, n³60, p. 53, May 2014

48. Guerra EM, Preparation and characterization of vanadium pentoxide mesopore and reactions of collation. Faculdade de Filosofia, Ciências e Letras de Ribeirão Preto, Universidade de São Paulo, Tese de Doutorado, 2007

49. Junior WA, Nanoparticles synthesis of vanadium oxide obtained by peroxide decomposition. Instituto de Física de São Carlos, Universidade de São Paulo, Tese de Doutorado, 2010

50. R.F.B. De Souza, L.S. Parreira, D.C. Rascio, J.C.M. Silva, E. Teixeira-Neto, M.L. Calegaro, E.V. Spinace, A.O. Neto, M.C. Santos, Study of ethanol electro-oxidation in acid environment on $\mathrm{Pt} 3 \mathrm{Sn} / \mathrm{C}$ anode catalysts prepared by a modified polymeric precursor method under controlled synthesis conditions. J. Power Sources 195(6), 1589-1593 (2010)

51. M.C. Santos, L. Cogo, S.T. Tanimoto, M.L. Calegaro, L.O.S. Bulhões, A nanogravimmetric investigation of the charging processes on ruthenium oxide thin films and their effect on methanol oxidation. Appl. Surf. Sci. 253(4), 1817-1822 (2006)

52. H.B. Suffredini, V. Tricoli, L.A. Avaca, N. Vatistas, Sol-gel method to prepare active $\mathrm{Pt}-\mathrm{RuO} 2$ coatings on carbon powder for methanol oxidation. Electrochem Communic 6(10), 1025-1028 (2004)

53. Karmanov I., Wetting or non-wetting liquid?. Phys. Edu. 2000 p.58, 77
54. A.P. Luz, S. Ribeiro, V.C. Pandolfelli, Review paper: use of wettability in the investigation of the corrosion behavior of refractory materials. Cerâmica 54, 174-183 (2008)

55. D.Y. Kwok, A.W. Neumann, Contact angle measuremente and contact angle interpretation. Adv. Colloid Interf. Sci. 81, 167-249 (1999)

56. U.A. Paulus, T.J. Schmidt, H.A. Gasteiger, R.J. Behm, Oxygen reduction on a high-surface area Pt/Vulcan carbon catalyst: a thinfilm rotating ring-disk electrode study. J. Electroanal. Chem. 495, 134-145 (2001)

57. Q. Tang, Y. Chen, Y. Yang, Understanding the nature of vanadium species supported on activated carbon and its catalytic properties in the aerobic oxidation of aromatic alcohols. J ec Catal A: Chem 315, 43-50 (2010)

58. B.M. Weckhuysen, D.E. Keller, Chemistry, spectroscopy and the role of supported vanadium oxides in heterogeneous catalysis. Catal. Today 78, 25-46 (2003)

59. M.C. Román-Martínez, D. Cazorla-Amorós, A. Linares-Solano, C.S.-M. De Lecea, H. Yamashita, M. Anpo, Metal-support interaction in $\mathrm{Pt} / \mathrm{C}$ catalysts. Influence of the support surface chemistry and the metal precursor. Carbon 33(1), 3-13 (1995)

60. R.C.M. Jakobs, L.J.J. Janssen, E. Barendrecht, Oxygen reduction at polypyrrole electrodes - I. Theory and evaluation of the RRDE experiments. Electrochim. Acta 30(8), 1085-1091 (1985)

61. X. Li, A.L. Zhu, W. Qu, H. Wang, R. Hui, L. Zhang, J. Zhang, Magneli phase Ti4O7 electrode for oxygen reduction reaction and its implication for zinc-air rechargeable batteries. Electrochim. Acta 55(20), 5891-5898 (2010)

62. L. Demarconnay, C. Coutanceau, J.M. Léger, Electroreduction of dioxygen (ORR) in alkaline medium on $\mathrm{Ag} / \mathrm{C}$ and $\mathrm{Pt} / \mathrm{C}$ nanostructured catalysts - effect of the presence of methanol. Electrochim. Acta 49(25), 4513-4521 (2004) 